\title{
EKSPERIMENTASI MODEL PEMBELAJARAN KOOPERATIF TIPE TAI BERBASIS AFL PADA PERSAMAAN GARIS LURUS DITINJAU DARI SIKAP SISWA TERHADAP MATEMATIKA
}

\author{
Adi Nurcahyo ${ }^{1}$ Budiyono $^{2}$, Budi Usodo $^{3}$ \\ ${ }^{1,2,3}$ Program Magister Pendidikan Matematika, FKIP Universitas Sebelas Maret Surakarta
}

\begin{abstract}
The purpose of this research was to determine the effect of learning models on mathematics achievement viewed from student attitude toward mathematics. The learning models compared were Team Assisted Individualization (TAI) based Assessment for Learning (AfL), TAI, and conventional learning model. The research was quasi experimental. The population of this research was all students of grade VIII State Junior High School of the District Karanganyar, academic year 2013/2014. The samples in this research were SMPN 1 Tasikmadu, SMPN 2 Jaten, and SMPN 2 Colomadu taken by stratified cluster random sampling. Instruments used to collect data were mathematics achievement instrument test and questionnaires students toward mathematics instrument. Data analysis technique used hypothesis test with two-way analysis of variance with unbalanced cells. From the results of the analysis, can be concluded that: 1) the learning achievement in mathematics of the students who were learning mathematics with cooperative learning model TAI Based AfL were better than the ones who were learning mathematics with cooperative learning model TAI and conventional learning model, however the students who were learning mathematics with cooperative learning model TAI were better than the ones who were learning mathematics with conventional learning model, 2) the learning achievement in mathematics of the students with the high attitude toward mathematics were better than the ones with the medium and low attitude toward mathematics, however the students with the medium attitude toward mathematics were better than the ones with the low attitude toward mathematics, 3) in the cooperative learning model TAI Based AfL, the learning achievement in mathematics of the students with ones who have the high attitude toward mathematics were better than the students with the low attitude toward mathematics, and students with the medium attitude toward mathematics were as good as the ones who have low attitude toward mathematics as well. In the cooperative learning model TAI and conventional learning model, the students with the high, medium, and low attitude toward mathematics had the same achievement in learning mathematics, 4) in the students with the high attitude toward mathematics, the learning achievement of the students who were learning mathematics with ones who have cooperative learning model TAI Based AfL were better than the students were learning mathematics with cooperative learning model TAI, the students who were learning mathematics with cooperative learning model TAI had the same achievement in learning mathematics with conventional learning model, and the students who were learning mathematics with cooperative learning model TAI Based AfL had the same achievement in learning mathematics with cooperative learning model TAI. The students with the medium and low attitude toward mathematics had the same achievement in learning mathematics among the ones who were given the cooperative learning model TAI Based AfL, TAI, and conventional learning model.

Keywords: Team Assisted Individualization (TAI), Assessment for learning (AfL), students attitude toward mathematics, achievement learning mathematics.
\end{abstract}

\section{PENDAHULUAN}

Pendidikan pada dasarnya adalah suatu proses untuk membantu manusia dalam mengembangkan dirinya, sehingga mampu menghadapi segala perubahan dan permasalahan yang dihadapi. Indonesia sebagai negara berkembang melakukan 
peningkatan kualitas dalam hal pendidikan dengan tujuan untuk meningkatkan kualitas sumber daya manusia Indonesia. Fungsi dan tujuan pendidikan yang tertuang dalam Undang-Undang Sisdiknas No. 20 tahun 2003 yaitu Pendidikan Nasional berfungsi mengembangkan kemampuan dan membentuk watak serta peradaban bangsa yang bermartabat dalam rangka mencerdaskan kehidupan bangsa, bertujuan untuk berkembangnya potensi siswa, agar menjadi manusia yang beriman dan bertaqwa kepada Tuhan Yang Maha Esa, berakhlak mulia, sehat, berilmu, cakap, kreatif, mandiri, dan menjadi warga negara yang demokratis serta bertanggung jawab.

Proses pembelajaran merupakan suatu kegiatan interaksi yang terjadi antara guru dan siswa di sekolah. Menurut Biggs dalam Goldman et al (2012) pembelajaran adalah suatu cara saling berinteraksi dengan dunia. Proses pembelajaran tidak hanya merupakan proses penyampaian ilmu pengetahuan dari guru kepada siswa yang hanya menjadikan siswa sebagai objek pembelajaran semata, tetapi senantiasa menjadikan siswa sebagai subjek dalam pembelajaran sehingga siswa menjadi aktif dan dapat mengembangkan kemampuan yang dimiliki. Oleh sebab itu, guru dituntut harus menguasai materi sekaligus mampu mengelola kelas dengan baik agar siswa mampu memahami materi dengan baik.

Berbagai upaya dilakukan pemerintah untuk meningkatkan kualitas pendidikan di Indonesia. Upaya dalam meningkatkan kualitas pendidikan telah dilakukan dengan memperbaiki pelaksanaan proses pembelajaran. Tetapi usaha-usaha yang telah dilakukan belum cukup menunjukkan hasil yang memuaskan. Hal ini dapat dilihat dari prestasi belajar yang ditunjukkan oleh siswa, khususnya pada mata pelajaran matematika. Padahal, mata pelajaran matematika mempunyai jam pembelajaran yang lebih banyak dibandingkan dengan mata pelajaran yang lain di sekolah.

Berdasarkan data dari Litbang Kemdiknas, nilai rata-rata Ujian Nasional Provinsi Jawa Tengah jauh di bawah rata-rata nasional yaitu 6,59 dengan rata-rata nasional 7,53 untuk mata pelajaran matematika. Wilayah yang perlu mendapat perhatian di Provinsi Jawa Tengah adalah Kabupaten Karanganyar. Nilai Ujian Nasional pada tahun ajaran 2009/2010 sampai tahun ajaran 2011/2012 mengalami penurunan. Hal itu terlihat dari penurunan nilai Ujian Nasional yang pada tahun ajaran 2009/2010 adalah 7,29 kemudian menurun menjadi 6,60 pada tahun ajaran 2010/2011, dan pada tahunajaran 2011/2012 menjadi 6,28. Hal tersebut menunjukkan bahwa ada permasalaan dalam mata pelajaran matematika dan siswa mengalami kesulitan dalam matematika sehingga perlua adanya peningkatan. Adapun persentase penguasaan materi menyelesaikan masalah yang berkaitan dengan menentukan gradien, persamaan garis, atau grafiknya di Kabupaten Karanganyar masih berada di bawah kemampuan daya serap Provinsi Jawa Tengah 
yaitu 52,55\%, sedangkan pada tingkat Provinsi Jawa Tengah mencapai 59,08\%. Begitu juga untuk daya serap Kabupaten Karanganyar masih berada di bawah daya serap tingkat Nasional yang mencapai $75,58 \%$. Hal ini menerangkan bahwa sebagian siswa di Kabupaten Karanganyar masih mengalami kesulitan dalam menyelesaikan masalah yang berkaitan dengan materi menentukan gradien, persamaan garis, atau grafiknya.

Untuk meningkatkan prestasi belajar siswa, perlu adanya suatu usaha yang lebih keras dari guru, terutama untuk menciptakan suatu suasana yang dapat memacu siswa untuk mengembangkan kemampuannya dengan baik. Untuk mewujudkan suasana yang dapat memacu siswa, guru dapat membuat suatu inovasi-inovasi baru yang inovatif dan menyenangkan. Hal itu dapat diwujudkan dengan menerapkan suatu model pembelajaran yang bervariasi dan sesuai dengan karakteristik siswa. Penggunaan suatu model pembelajaran diharapkan dapat membantu kelancaran, efektifitas, dan efisiensi pencapaian tujuan pembelajaran. Dengan hal tersebut diharapkan siswa dapat dengan mudah memahami segala materi yang diajarkan oleh guru dan dapat menyelesaikan permasalahan-permasalahan matematika dengan tepat. Model pembelajaran yang digunakan juga harus sesuai dengan pendekatan konstruktivisme dan berorientasi pada siswa. Dalam teori belajar konstruktivisme semua pengetahuan adalah hasil konstruksi dari kegiatan atau tindakan seseorang (Agus Suprijono, 2011: 31). Salah satu model pembelajaran yang diharapkan berorientasi pada siswa adalah model pembelajaran kooperatif. Hal ini berdasarkan pernyataan Johnson, Johnson and Holubec dalam Attle \& Parker (2007) yang menyebutkan bahwa Pembelajaran kooperatif meningkatkan upayaupaya di kalangan siswa, hubungan interpersonal yang lebih positif, dan kesehatan mental meningkat jika dibandingkan dengan pembelajaran individualistik. Dengan belajar secara kooperatif siswa diharapkan lebih aktif secara individu dan memiliki kemampuan interaksi yang baik antar teman dalam kelompok-kelompok, sehingga diharapkan siswa dapat mengembangkan sendiri pengetahuan yang dimiliki. Keterlibatan dengan orang lain membuka kesempatan bagi peserta didik untuk mengevaluasi dan memperbaiki pemahaman mereka saat mereka bertemu dengan pemikiran orang lain dan saat mereka berpartisipasi dalam pencarian pemahaman bersama. (Agus Suprijono, 2011: 39-40). Sehingga, model pembelajaran ini dalam pelaksanaan proses pembelajarannya menggunakan pendekatan konstruktivisme yang memberikan kerangka pemikiran belajar sebagai proses sosial atau belajar kolaboratif dan kooperatif.

Model pembelajaran yang termasuk model pembelajaran kooperatif diantaranya adalah model pembelajaran kooperatif Team Assissted Individualization (TAI). Slavin (2010: 189) mengemukakan bahwa Matematika TAI diprakarsai sebagai usaha 
merancang sebuah bentuk pengajaran individual yang bisa menyelesaikan masalahmasalah yang membuat metode pengajaran individual menjadi tidak efektif. TAI dirancang untuk memperoleh manfaat yang sangat besar dari potensi sosialisasi yang terdapat dalam pembelajaran kooperatif. Hal tersebut sesuai dengan hasil penelitian Tarim \& Akdeniz (2007) yang memberikan kesimpulan TAI lebih efektif daripada STAD dan metode tradisional dalam meningkatkan prestasi belajar siswa. Unsur-unsur TAI menurut Slavin (2010: 195-200) adalah tim, tes penempatan, materi-materi kurikulum, belajar kelompok yang meliputi latihan kemampuan, tes formatif $\mathrm{A}$, dan tes formatif B, skor tim dan rekognisi tim, kelompok pengajaran, tes fakta dan unit seluruh kelas.

Salah satu jenis asesmen yang telah lama dikembangkan untuk pembelajaran adalah Assessment for Learning (AfL). Menurut Irving (2006) dampak positif yang dapat dilakukan dengan memaksimalkan pengukuran tentang prestasi siswa dapat dilakukan dengan asesmen untuk pembelajaran. Dalam hal ini, asesmen untuk pembelajaran merupakan asesmen formatif. Menurut Budiyono (2011: 58) fungsi asesmen formatif sebagai wahana untuk memberikan balikan (feed-back) kepada siswa secepat mungkin. Menurut Clarke dalam Budiyono (2011: 60) pelaksanaan AfL harus mengikuti strategi diantaranya menyatakan dengan jelas tujuan pembelajaran dan kriteria sukses pada perencanaan pembelajaran sebagai kerangka dasar untuk AfL, berbagi tujuan pembelajaran dan kriteria sukses dengan siswa, dan memusatkan pada pemberian balikan secara lisan maupun tertulis.

Menurut Slavin dan Karweit dalam Tarim \& Akdeniz (2007) yang menyatakan bahwa model pembelajaran kooperatif memberikan pengaruh yang positif mengenai sikap siswa terhadap matematika. Sikap siswa terhadap matematika mencerminkan bagaimana seseorang merasakan sesuatu dalam matematika. Menurut Cagirgan (2012) sikap melibatkan keyakinan, perasaan, nilai-nilai individu, dan disposisi untuk bertindak dengan cara tertentu dari pilihan individu. Setiap individu dalam melakukan aktivitasnya akan didasarkan atas sikapnya tentang aktivitas yang akan dilaksanakannya. Sikap siswa terhadap matematika meliputi siswa dengan sikap tinggi, sedang dan rendah. Masingmasing mempunyai pengaruh terhadap prestasi belajar matematika. Seperti yang dinyatakan oleh Erny Untari (2012) dalam penelitiannya tentang materi persamaan garis lurus bahwa semakin tinggi sikap siswa terhadap matematika, semakin tinggi pula prestasi belajar matematikanya.

Tujuan dari penelitian ini untuk mengetahui: 1) manakah yang mempunyai prestasi belajar matematika yang lebih baik, siswa yang dikenai model pembelajaran kooperatif TAI, TAI berbasis AfL, atau pembelajaran konvensional, 2) manakah yang 
mempunyai prestasi belajar matematika yang lebih baik, siswa yang memiliki sikap terhadap matematika dengan kategori tinggi, sedang, atau rendah, 3) pada masing-masing tipe model pembelajaran, manakah yang mempunyai prestasi belajar matematika yang lebih baik, siswa yang memiliki sikap terhadap matematika dengan kategori tinggi, sedang, atau rendah, 4) pada masing-masing kategori sikap siswa terhadap matematika, manakah yang mempunyai prestasi belajar matematika yang lebih baik, siswa yang dikenai model pembelajaran kooperatif TAI, TAI berbasis AfL, atau pembelajaran konvensional.

\section{METODE PENELITIAN}

Penelitian ini dilaksanakan pada semester I tahun pelajaran 2013/2014 dengan jenis penelitian eksperimental semu dan desain faktorial $3 \times 3$. Tabel rancangan penelitian disajikan dalam Tabel 1 berikut:

Tabel 1. Rancangan Penelitian

\begin{tabular}{lccc}
\hline \multirow{2}{*}{ Model Pembelajaran $(\mathrm{A})$} & \multicolumn{3}{c}{ Sikap Siswa terhadap Matematika $(\mathrm{B})$} \\
\cline { 2 - 4 } & Tinggi $\left(\mathrm{b}_{1}\right)$ & Sedang $\left(\mathrm{b}_{2}\right)$ & Rendah $\left(\mathrm{b}_{3}\right)$ \\
\hline TAI Berbasis AfL $\left(\mathrm{a}_{1}\right)$ & $(\mathrm{ab})_{11}$ & $(\mathrm{ab})_{12}$ & $(\mathrm{ab})_{13}$ \\
TAI $\left(\mathrm{a}_{2}\right)$ & $(\mathrm{ab})_{21}$ & $(\mathrm{ab})_{22}$ & $(\mathrm{ab})_{23}$ \\
Konvensional $\left(\mathrm{a}_{3}\right)$ & $(\mathrm{ab})_{31}$ & $(\mathrm{ab})_{32}$ & $(\mathrm{ab})_{33}$ \\
\hline
\end{tabular}

Populasi penelitian ini adalah seluruh siswa kelas VIII SMP se-Kabupaten Karanganyar. Sampel diambil secara acak dari populasi dengan teknik stratified cluster random sampling. Berdasarkan teknik pengambilan sampel tersebut, terpilih SMPN 1 Tasikmadu mewakili kelompok tinggi, SMPN 2 Jaten kelompok sedang dan SMPN 2 Colomadu mewakili kelompok rendah.

Dalam penelitian ini terdapat dua variabel yaitu variabel bebas dan terikat. Variabel bebas meliputi model pembelajaran dan sikap siswa terhadap matematika. Sedangkan variabel terikat yaitu prestasi belajar matematika. Untuk mengumpulkan data digunakan metode dokumentasi, metode angket, dan metode tes. Metode dokumentasi digunakan untuk mendapatkan data kemampuan awal berupa nilai UAS semester genap kelas VII. Metode angket digunakan untuk memperoleh data kategori sikap siswa terhadap matematika dan metode tes digunakan untuk mengumpulkan data prestasi belajar matematika siswa pada materi persamaan garis lurus.

Teknik analisis data yang digunakan adalah analisis variansi dua jalan dengan sel tak sama. Sebelum diberi perlakuan, dilakukan uji normalitas dengan menggunakan uji Lilliefors dan uji homogenitas variansi menggunakan metode Barttlet. Selanjutnya dilakukan uji keseimbangan dengan analisis variansi satu jalan untuk mengetahui apakah 
kelompok eksperimen dan kelompok kontrol mempunyai kemampuan awal seimbang atau tidak.

\section{HASIL PENELITIAN DAN PEMBAHASAN}

Setelah dilakukan uji keseimbangan, diperoleh simpulan bahwa kemampuan awal masing-masing populasi adalah sama. Selanjutnya dilakukan uji hipotesis penelitian pada data prestasi belajar siswa, dengan sebelumnya dilakukan uji normalitas dan uji homogenitas variansi pada data penelitian. Rangkuman rerata masing-masing sel dan rerata marginal dapat dilihat pada Tabel 2.

Tabel 2 Rerata Masing-Masing Sel dan Rerata Marginal

\begin{tabular}{lcccc}
\hline \multirow{2}{*}{$\begin{array}{c}\text { Model } \\
\text { Pembelajaran }\end{array}$} & \multicolumn{2}{c}{ Sikap Siswa terhadap Matematika } & \\
\cline { 2 - 4 } & Tinggi $\left(\mathrm{b}_{1}\right)$ & Sedang $\left(\mathrm{b}_{2}\right)$ & Rendah $\left(\mathrm{b}_{3}\right)$ & Rerata Marginal \\
\hline TAI-AFL $\left(\mathrm{a}_{1}\right)$ & 69.75 & 62.84 & 49.38 & 61.50 \\
TAI $\left(\mathrm{a}_{2}\right)$ & 63.17 & 52.00 & 49.23 & 54.57 \\
LANGSUNG $\left(\mathrm{a}_{3}\right)$ & 50.07 & 48.73 & 46.63 & 48.43 \\
Rerata Marginal & 61.29 & 54.67 & 48.29 & \\
\hline
\end{tabular}

Adapun rangkuman perhitungan analisis variansi dua jalan dengan sel tak sama disajikan dalam Tabel 3.

Tabel 3 Rangkuman Analisis Variansi Dua Jalan dengan Sel Tak Sama

\begin{tabular}{lcccccl}
\hline Sumber & JK & $\mathbf{d k}$ & $\mathbf{R K}$ & $\boldsymbol{F}_{\text {obs }}$ & $\boldsymbol{F}_{\boldsymbol{\alpha}}$ & Keputusan \\
\hline Model Pembelajaran (A) & 6957.00 & 2 & 3478.50 & 13.05 & 3.03 & $H_{0}$ ditolak \\
Sikap Siswa terhadap & 7417.89 & 2 & 3708.94 & 13.92 & 3.03 & $H_{0}$ ditolak \\
Matematika (B) & 2869.73 & 4 & 717.43 & 2.69 & 2.37 & $H_{0}$ ditolak \\
Interaksi (AB) & 33843.26 & 279 & 266.51 & - & - & - \\
Galat & 91600.48 & 287 & - & & - & - \\
Total & & & & &
\end{tabular}

Berdasarkan Tabel 3 diperoleh kesimpulan bahwa: 1) model pembelajaran berpengaruh terhadap prestasi belajar matematika siswa, 2) sikap siswa terhadap matematika berpengaruh terhadap prestasi belajar matematika siswa, 3) terdapat interaksi antara model pembelajaran dan sikap siswa terhadap matematika.

Dari hasil perhitungan anava dua jalan dengan sel tak sama diperoleh $\mathrm{H}_{0 \mathrm{~A}}$ ditolak, selanjutnya dilakukan uji komparasi rerata antar baris dengan metode Scheffe. Rangkuman hasil uji lanjut rerata antar baris disajikan dalam Tabel 4.

Tabel 4 Rangkuman Hasil Komparasi Rerata Antar Baris

\begin{tabular}{cccccc}
\hline Komparasi & $\mathrm{H}_{0}$ & $\mathrm{H}_{1}$ & $\mathrm{~F}_{\text {obs }}$ & $2 \mathrm{~F}_{0,05 ; 2 ; 279}$ & Keputusan \\
\hline$\mu_{1 .}$ vs $\mu_{2 .}$ & $\mu_{1 .}=\mu_{2 .}$ & $\mu_{1 .} \neq \mu_{2 .}$ & 8.74 & 6.06 & $H_{0}$ ditolak \\
$\mu_{2 .}$ vs $\mu_{3 .}$ & $\mu_{2 .}=\mu_{3 .}$ & $\mu_{2 .} \neq \mu_{3 .}$ & 6.79 & 6.06 & $H_{0}$ ditolak \\
$\mu_{1 .}$ vs $\mu_{3 .}$ & $\mu_{1 .}=\mu_{3 .}$ & $\mu_{1 .} \neq \mu_{3 .}$ & 30.44 & 6.06 & $H_{0}$ ditolak \\
\hline
\end{tabular}

Berdasarkan Tabel 4 dan dengan melihat Tabel 2 dapat disimpulkan bahwa prestasi belajar siswa yang dikenai model pembelajaran kooperatif TAI Berbasis AfL berbeda dengan siswa yang dikenai model pembelajaran kooperatif TAI, prestasi belajar 
siswa yang dikenai model pembelajaran kooperatif TAI berbeda dengan siswa yang dikenai model pembelajaran konvensional, dan prestasi belajar siswa yang dikenai model pembelajaran kooperatif TAI Berbasis AfL berbeda dengan siswa yang dikenai model pembelajaran konvensional. Dengan melihat rerata marginal pada Tabel 2, prestasi belajar siswa yang dikenai model pembelajaran kooperatif TAI Berbasis AfL lebih baik dari model pembelajaran kooperatif TAI dan model pembelajaran konvensional, model pembelajaran kooperatif TAI lebih baik dari model pembelajaran konvensional. Hal ini dikarenakan AfL merupakan proses mencari dan menginterpretasikan fakta-fakta yang digunakan oleh peserta didik dan guru untuk menentukan dimana peserta didik belajar, apa yang mereka butuhkan, dan bagaimana mencapai hasil yang terbaik. Hasil ini sesuai dengan penelitian Rahayu (2011) bahwa penggunaan model pembelajaran kooperatif tipe Teams Games Tournaments (TGT) yang dimodifikasi dengan Assesment for Learning (AfL) pada pembelajaran aplikasi turunan fungsi menghasilkan prestasi belajar siswa lebih baik daripada penggunaan model pembelajaran kooperatif Teams Games Tournament (TGT).

Dari hasil perhitungan anava diperoleh $\mathrm{H}_{0 \mathrm{~B}}$ ditolak, kemudian dilakukan uji komparasi rerata antar kolom dengan metode Scheffe. Rangkuman perhitungan uji lanjut rerata antar kolom disajikan dalam Tabel 5.

Tabel 5 Rangkuman Hasil Komparasi Rerata Antar Kolom

\begin{tabular}{cccccc}
\hline Komparasi & $\mathrm{H}_{0}$ & $\mathrm{H}_{1}$ & $\mathrm{~F}_{\text {obs }}$ & $2 \mathrm{~F}_{0,05 ; 2 ; 279}$ & Keputusan \\
\hline$\mu_{.1}$ vs $\mu_{.2}$ & $\mu_{.1}=\mu_{.2}$ & $\mu_{.1} \neq \mu_{.2}$ & 8.27 & 6.06 & $H_{0}$ ditolak \\
$\mu_{.2}$ vs $\mu_{3 .}$ & $\mu_{.2}=\mu_{.3}$ & $\mu_{.2} \neq \mu_{3}$ & 7.39 & 6.06 & $H_{0}$ ditolak \\
$\mu_{.1}$ vs $\mu_{3}$ & $\mu_{.1}=\mu_{.3}$ & $\mu_{.1} \neq \mu_{.3}$ & 27.55 & 6.06 & $H_{0}$ ditolak \\
\hline
\end{tabular}

Berdasarkan Tabel 5 dan dengan melihat Tabel 2 dapat disimpulkan bahwa prestasi belajar siswa yang memiliki sikap tinggi terhadap matematika berbeda dengan siswa yang memiliki sikap sedang terhadap matematika, prestasi belajar siswa yang memiliki sikap sedang terhadap matematika berbeda dengan siswa yang memiliki sikap rendah terhadap matematika, dan prestasi belajar siswa yang memiliki sikap tinggi terhadap matematika berbeda dengan siswa yang memiliki sikap rendah terhadap matematika. Dengan melihat rerata marginal pada Tabel 2, prestasi belajar siswa yang memiliki sikap terhadap matematika tinggi lebih baik daripada sikap terhadap matematika sedang dan rendah, sikap terhadap matematika sedang lebih baik daripada sikap terhadap matematika rendah. Hal ini sesuai dengan penelitian yang dilakukan oleh Erny Untari (2012) yang menyatakan bahwa siswa dengan sikap tinggi memiliki prestasi yang lebih baik daripada siswa dengan sikap sedang maupun rendah terhadap matematika, dan siswa dengan sikap sedang memiliki prestasi belajar lebih baik daripada siswa dengan sikap rendah terhadap matematika. 
Berdasarkan perhitungan diperoleh $\mathrm{H}_{0 \mathrm{AB}}$ ditolak, kemudian dilakukan uji komparasi rerata antar sel dengan metode Scheffe. Rangkuman hasil uji lanjut rerata antar sel pada baris yang sama disajikan dalam Tabel 6.

Tabel 6 Rangkuman Hasil Komparasi Rerata Antar Sel pada Baris yang Sama

\begin{tabular}{cccccc}
\hline Komparasi & $\mathrm{H}_{0}$ & $\mathrm{H}_{1}$ & $\mathrm{~F}_{\text {obs }}$ & $8 \mathrm{~F}_{0,05 ; 8 ; 279}$ & Keputusan \\
\hline$\mu_{11}$ vs $\mu_{12}$ & $\mu_{11}=\mu_{12}$ & $\mu_{11} \neq \mu_{12}$ & 3.110398 & $(8)(1,94)=15,2$ & $H_{0}$ diterima \\
$\mu_{12}$ vs $\mu_{13}$ & $\mu_{12}=\mu_{13}$ & $\mu_{12} \neq \mu_{13}$ & 10.49045 & $(8)(1,94)=15,2$ & $H_{0}$ diterima \\
$\mu_{11}$ vs $\mu_{13}$ & $\mu_{11}=\mu_{13}$ & $\mu_{11} \neq \mu_{13}$ & 22.32387 & $(8)(1,94)=15,2$ & $H_{0}$ ditolak \\
$\mu_{21}$ vs $\mu_{22}$ & $\mu_{21}=\mu_{22}$ & $\mu_{21} \neq \mu_{22}$ & 8.111795 & $(8)(1,94)=15,2$ & $H_{0}$ diterima \\
$\mu_{22}$ vs $\mu_{23}$ & $\mu_{22}=\mu_{23}$ & $\mu_{22} \neq \mu_{23}$ & 0.466230 & $(8)(1,94)=15,2$ & $H_{0}$ diterima \\
$\mu_{21}$ vs $\mu_{23}$ & $\mu_{21}=\mu_{23}$ & $\mu_{21} \neq \mu_{23}$ & 9.998288 & $(8)(1,94)=15,2$ & $H_{0}$ diterima \\
$\mu_{31}$ vs $\mu_{32}$ & $\mu_{31}=\mu_{32}$ & $\mu_{31} \neq \mu_{32}$ & 0.104259 & $(8)(1,94)=15,2$ & $H_{0}$ diterima \\
$\mu_{32}$ vs $\mu_{33}$ & $\mu_{32}=\mu_{33}$ & $\mu_{32} \neq \mu_{33}$ & 0.269412 & $(8)(1,94)=15,2$ & $H_{0}$ diterima \\
$\mu_{31}$ vs $\mu_{33}$ & $\mu_{31}=\mu_{33}$ & $\mu_{31} \neq \mu_{33}$ & 0.677056 & $(8)(1,94)=15,2$ & $H_{0}$ diterima \\
\hline
\end{tabular}

Berdasarkan Tabel 6 dan dengan melihat Tabel 2 dapat disimpulkan bahwa pada model pembelajaran kooperatif TAI Berbasis AfL siswa yang memiliki sikap tinggi terhadap matematika memiliki prestasi belajar yang lebih baik daripada siswa yang memilki sikap rendah terhadap matematika. Siswa yang memiliki sikap tinggi terhadap matematika memiliki prestasi belajar yang sama baiknya dengan siswa yang memiliki sikap sedang terhadap matematika dan siswa yang memiliki sikap sedang terhadap matematika memiliki prestasi belajar yang sama baiknya dengan siswa yang memiiki sikap rendah terhadap matematika. Pada model pembelajaran kooperatif TAI, siswa yang memiliki sikap tinggi terhadap matematika memiliki prestasi belajar yang sama baiknya dengan siswa yang memiliki sikap rendah terhadap matematika dan sikap rendah terhadap matematika. Pada model pembelajaran langsung, siswa dengan sikap tinggi terhadap matematika memiliki prestasi yang sama baiknya dengan siswa yang memiliki sikap sedang terhadap matematika dan sikap rendah terhadap matematika. Ketidaksesuaian hipotesis penelitian dengan hasil penelitian ini dimungkinkan dalam pelaksanaan pada model pembelajaran kooperatif TAI terdapat faktor lain yang mempengaruhi. Oemar Hamalik dalam Widayati (2009) menyatakan bahwa terdapat faktor-faktor yang mempengaruhi belajar siswa diantaranya adalah belajar dilakukan dalam suasana yang menyenangkan, siswa telah siap belajar, siswa mempunyai minat yang dapat mendorong siswa belajar lebih baik. Minat siswa meliputi minat yang muncul dari dalam diri maupun minat yang berasal dari luar diri. Adanya minat dapat memberikan pengaruh dalam belajar karena mendorong siswa untuk belajar lebih serius dan lebih memusatkan perhatian pada pelajaran yang diberikan.

Kemudian berikut disajikan rangkuman perhitungan uji lanjut rerata antar sel pada kolom yang sama dalam Tabel 7. 
Tabel 7 Rangkuman Hasil Komparasi Rerata Antar Sel pada Kolom yang Sama

\begin{tabular}{cccccc}
\hline Komparasi & $\mathrm{H}_{0}$ & $\mathrm{H}_{1}$ & $\mathrm{~F}_{\text {obs }}$ & $8 \mathrm{~F}_{0,05 ; 8 ; 279}$ & Keputusan \\
\hline$\mu_{11}$ vs $\mu_{21}$ & $\mu_{11}=\mu_{21}$ & $\mu_{11} \neq \mu_{21}$ & 2.46968 & $(8)(1,94)=15,2$ & $H_{0}$ diterima \\
$\mu_{21}$ vs $\mu_{31}$ & $\mu_{21}=\mu_{31}$ & $\mu_{21} \neq \mu_{31}$ & 0.01111 & $(8)(1,94)=15,2$ & $H_{0}$ diterima \\
$\mu_{11}$ vs $\mu_{31}$ & $\mu_{11}=\mu_{31}$ & $\mu_{11} \neq \mu_{31}$ & 22.1107 & $(8)(1,94)=15,2$ & $H_{0}$ ditolak \\
$\mu_{12}$ vs $\mu_{22}$ & $\mu_{12}=\mu_{22}$ & $\mu_{12} \neq \mu_{22}$ & 8.89781 & $(8)(1,94)=15,2$ & $H_{0}$ diterima \\
$\mu_{22}$ vs $\mu_{32}$ & $\mu_{22}=\mu_{32}$ & $\mu_{22} \neq \mu_{32}$ & 0.00053 & $(8)(1,94)=15,2$ & $H_{0}$ diterima \\
$\mu_{12}$ vs $\mu_{32}$ & $\mu_{12}=\mu_{32}$ & $\mu_{12} \neq \mu_{32}$ & 13.2032 & $(8)(1,94)=15,2$ & $H_{0}$ diterima \\
$\mu_{13}$ vs $\mu_{23}$ & $\mu_{13}=\mu_{23}$ & $\mu_{13} \neq \mu_{23}$ & 0.00115 & $(8)(1,94)=15,2$ & $H_{0}$ diterima \\
$\mu_{23}$ vs $\mu_{33}$ & $\mu_{23}=\mu_{33}$ & $\mu_{23} \neq \mu_{33}$ & 0.00044 & $(8)(1,94)=15,2$ & $H_{0}$ diterima \\
$\mu_{13}$ vs $\mu_{33}$ & $\mu_{13}=\mu_{33}$ & $\mu_{13} \neq \mu_{33}$ & 0.40990 & $(8)(1,94)=15,2$ & $H_{0}$ diterima \\
\hline
\end{tabular}

Berdasarkan Tabel 7 dan dengan melihat Tabel 2 dapat disimpulkan bahwa pada siswa yang memiliki sikap tinggi terhadap matematika, siswa yang dikenai model pembelajaran kooperatif TAI Berbasis AfL memiliki prestasi belajar lebih baik daripada siswa yang dikenai model pembelajaran langsung. Siswa yang dikenai model pembelajaran kooperatif TAI memiliki prestasi belajar yang sama baiknya dengan siswa yang dikenai model pembelajaran Langsung, dan siswa yang dikenai model pembelajaran kooperatif TAI Berbasis AfL memiliki prestasi belajar yang sama baiknya dengan siswa yang dikenai model pembelajaran kooperatif TAI. Hal ini dikarenakan siswa dengan sikap tinggi terhadap matematika dapat meningkatkan prestasi belajar matematika dengan adanya model pembelajaran TAI Berbasis AfL, karena feedback pada AfL berfungsi untuk memberikan balikan kepada siswa mengenai hal-hal yang belum dimengerti. Sehingga siswa dapat memperbaiki kesalahannya. Pada siswa yang memiliki sikap sedang terhadap matematika, memiliki prestasi belajar yang sama antara siswa yang dikenai model pembelajaran kooperatif TAI Berbasis AfL, TAI, dan konvensional. Pada siswa yang memiliki sikap rendah terhadap matematika, memiliki prestasi belajar yang sama antara siswa yang dikenai model pembelajaran kooperatif TAI Berbasis AfL, TAI, dan konvensional.

\section{SIMPULAN DAN SARAN}

Berdasarkan analisis data penelitian yang dilakukan, dapat disimpulkan sebagai berikut. (1) prestasi belajar matematika siswa dengan menggunakan model pembelajaran kooperatif TAI Berbasis AfL lebih baik daripada menggunakan model pembelajaran kooperatif TAI dan model pembelajaran langsung serta prestasi belajar matematika siswa dengan menggunakan model pembelajaran kooperatif TAI lebih baik daripada menggunakan model pembelajaran langsung pada materi persamaan garis lurus, (2) sikap siswa terhadap matematika memberikan pengaruh yang berbeda terhadap prestasi belajar matematika siswa pada materi persamaan garis lurus. Siswa yang memiliki sikap tinggi terhadap matematika memiliki prestasi belajar yang lebih baik daripada siswa yang 
memiliki sikap sedang dan sikap rendah terhadap matematika serta siswa yang memiliki sikap sedang terhadap matematika lebih baik prestasi belajarnya daripada siswa yang memiliki sikap rendah terhadap matematika, (3) pada model pembelajaran kooperatif TAI Berbasis AfL, siswa dengan sikap tinggi terhadap matematika memiliki prestasi belajar matematika yang lebih baik daripada siswa yang memiliki sikap rendah terhadap matematika. Siswa yang memiliki sikap tinggi terhadap matematika memiliki prestasi yang sama baiknya dengan siswa yang memiliki sikap rendah terhadap matematika, dan siswa yang memiliki sikap sedang terhadap matematika memiliki prestasi belajar yang sama baiknya dengan siswa yang memiliki sikap rendah terhadap matematika. Pada model pembelajaran kooperatif TAI dan model pembelajaran langsung, siswa dengan sikap tinggi, sedang, dan rendah terhadap matematika memiliki prestasi belajar yang sama baiknya, (4) Pada siswa dengan sikap tinggi terhadap matematika, siswa yang dikenai model pembelajaran kooperatif TAI Berbasis AfL memiliki prestasi belajar yang lebih baik daripada siswa yang dikenai model pembelajaran langsung, Siswa yang dikenai model pembelajaran kooperatif TAI memiliki prestasi belajar matematika sama baiknya dengan siswa yang dikenai model pembelajaran Langsung, dan siswa yang dikenai model pembelajaran kooperatif TAI Berbasis AfL memiliki prestasi belajar matematika yang sama baiknya dengan siswa yang dikenai model pembelajaran kooperatif TAI. Sedangkan siswa dengan sikap sedang terhadap matematika dan siswa dengan sikap rendah terhadap matematika memiliki prestasi belajar yang sama antara siswa yang dikenai model pembelajaran kooperatif TAI Berbasis AfL, model pembelajaran kooperatif TAI, dan model pembelajaran langsung pada materi persamaan garis lurus.

Saran dari penelitian ini adalah sebagai berikut. (1) Guru disarankan untuk menggunakan model pembelajaran kooperatif TAI Berbasis AfL. Dengan model pembelajaran kooperatif ini siswa akan lebih aktif dalam menyelesaikan masalah yang diberikan dan lebih mengefektifkan diskusi kelompok maupun antar kelompok dalam satu kelas. Selain itu dengan adanya balikan yang diberikan, guru dapat mengetahui kesulitan yang dialami oleh siswa dan siswa dapat mengetahui hal-hal yang belum dipahami. Guru hendaknya memperhatikan faktor lain dari dalam diri siswa yaitu sikap siswa terhadap matematika, karena dalam penelitian ini sikap siswa terhadap matematika memberikan pengaruh terhadap prestasi belajar siswa. Guru dapat menggunakan model pembelajaran kooperatif TAI Berbasis AfL dalam pembelajaran di kelas pada siswa dengan sikap tinggi terhadap matematika. Penerapan model pembelajaran kooperatif TAI Berbasis AfL dapat membantu siswa untuk memahami hal-hal yang belum dimengerti, sehingga prestasi belajar siswa meningkat. Selain itu, adanya feedback juga dapat menjadi sarana bagi guru untuk mengetahui sejauh mana pemahaman siswa pada suatu 
materi. Sedangkan pada siswa dengan sikap sedang dan rendah terhadap matematika, guru dapat menerapkan model pembelajaran kooperatif TAI maupun model pembelajaran kooperatif TAI Berbasis AfL sebagai alternatif lain selain model pembelajaran konvensional. Sehingga guru dapat mengoptimalkan sikap siswa terhadap matematika untuk meningkatkan prestasi belajar matematika siswa. (2) Siswa hendaknya dalam kegiatan pembelajaran ikut aktif, berani dan kritis dalam mengungkapkan ide-ide yang ada dalam diri masing-masing, sehingga dapat mengkonstruksi ide-ide dalam pembelajaran matetmatika. Selain itu, siswa hendaknya memahami sikap siswa terhadap matematika yang dimiliki masing-masing individu, sehingga tahu langkah-langkah apa yang harus diambil dan diharapkan prestasi belajar matematika siswa menjadi lebih meningkat. (3) Peneliti lain disarankan dapat meneruskan atau mengembangkan penelitian ini dengan menggunakan variabel lain maupun pembelajaran kooperatif yang lain sehingga dapat menambah wawasan dan pendidikan.

\section{DAFTAR PUSTAKA}

Attle, S and Parker, B. 2007. Cooperative Learning in a Competitive Environment: Classroom Applications. International Journal of Teaching and Learning in Higher Education. Volume 19, Number 1, 77-83 ISSN 1812-9129.

Budiyono. 2011. Penilaian Hasil Belajar. Surakarta: Universitas Sebelas Maret.

Cagirgan, DG. 2012. The Relationship Between Elementary Student's Attitude Towards Mathematics and Atudying to Mathematics. International Journal on New Trends in Education and Their Implications. Volume: 3 Issue: 1. ISSN 1309-6249.

Erny Untari. 2012. Efektivitas Model Pembelajaran Kooperatif Tipe Student Teams Achievement Divisions (STAD) dan Tipe Jigsaw pada Prestasi Belajar Matematika Ditinjau dari Sikap Siswa Terhadap Matematika Siswa SMP di Kabupaten Magetan. Tesis. Prodi Pendidikan Matematika Program Pasca Sarjana UNS, Surakarta.

Goldman, D.G.J., Torrisi, G., Steele. 2002. Contructivist Pedagogies Of Interactivity On A Cd-Rom To Enhance Academic Learning At A Tertiary Institusion, International Journal of Education Technology. Volume 3, page 155-165.

Irving, KE. 2006. The Impact of Educational Technology on Student Achievement: Assessment of and for Learning. ProQuest Agriculture Journals. page. 13.

Rahayu. 2011. Eksperimentasi model pembelajaran kooperatif tipe Teams Games Tournament (TGT) yang dimodifikasi dengan Assessment for Learning pada pokok bahasan aplikasi turunan fungsi ditinjau dari perhatian orang tua siswa kelas XI IPA SMA Negeri di Surakarta. Tesis. Prodi Pendidikan Matematika Program Pasca Sarjana UNS, Surakarta.

Slavin, R. 2010. Cooperative Leaarning Teori, Riset, dan Praktik. Nusa Media: Bandung 
Agus Suprijono. 2011. Cooperative Learning Teori dan Aplikasi Paikem. Pustaka pelajar: Yogyakarta.

Tarim, K dan Akdeniz, F. 2007. The Effects of Cooperatif Learning on Turkish Elementary Students' Mathematics Achievement and Attitude Towards Mathematics Using TAI and STAD Methods. Educational Studies in mathematics. Vol 67, Issue I pp 67-91.

Widayati, TS. 2009. Efektivitas Model Pembelajaran Portofolio Terhadap Hasil Belajar Matematika Ditinjau dari Sikap Siswa Terhadap Matematika Kelas XI IPS SMA Negeri di Kabupaten Klaten Tahun Pelajaran 2008/2009. Tesis. Surakarta: Universitas Sebelas Maret. Tidak Diterbitkan. 